\title{
PRÜFUNGSTHEMA: Psychische Störungen
}

\section{Liebe Heilpraktikeranwärter - hier ist Ihre Seite. In dieser Ausgabe beschäftigen sich alle Prüfungsfragen mit PSYCHISCHEN STÖRUNGEN. Viel Erfolg beim Beantworten wünscht Ihnen HP Eva C. Schmid!}

\section{Schriftliche Prüfungsfragen}

(Bitte kreuzen Sie je eine Antwort an.)

\section{FRAGE 1:}

Welche Aussagen über ADHS treffen zu?

1. Die Symptomatik tritt nur im Schulunterricht auf.

2. Erwachsene sind generell nicht betroffen.

3. Die Symptome treten erstmals meist vor dem 7. Lebensjahr auf.

4. Betroffene sind in der Regel hochbegabt.

5. In sozialen Beziehungen zeigt sich oft ein distanzloses Verhalten.

$\square$ a Aussagen 1 und 4 sind richtig.

$\square$ b Aussagen 2 und 5 sind richtig.

$\square \mathrm{c}$ Aussagen 3 und 5 sind richtig.

$\square \mathrm{d}$ Aussagen 2, 3 und 5 sind richtig.

$\square$ e Aussagen 1, 3, 4 und 5 sind richtig.
FRAGE 2:

Welches der folgenden Symptome wird den formalen Denkstörungen

zugeordnet?

$\square$ a Konkretismus

$\square$ b Parathymie

$\square$ c Nihilistischer Wahn

$\square$ d Katalepsie

$\square$ e Pareidolie

\section{FRAGE 3:}

Bei einem Patienten bemerken Sie kauende, grimassierende Bewegungen im Mundbereich. Die Anamnese zeigt, dass er jahrelang mit Haloperidol behandelt worden ist. Welche Aussagen treffen zu? 1. Die Medikamenteneinnahme spricht für Epilepsie.

2. Haloperidol wirkt antipsychotisch.

3. Der Patient könnte unter Spätdyskinesien leiden.

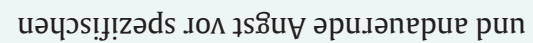

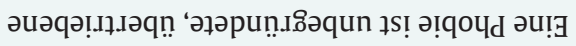

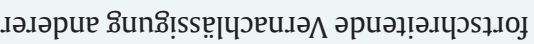

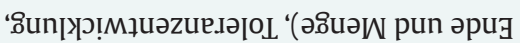

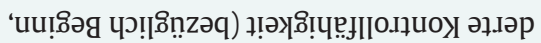

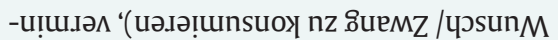

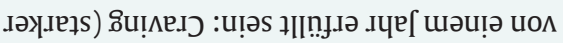

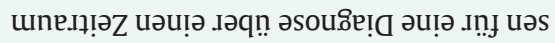

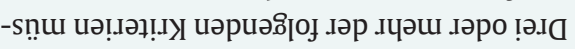

: $\exists$ IVy

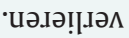

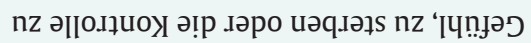

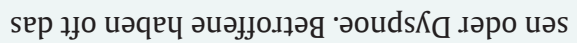

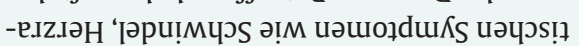

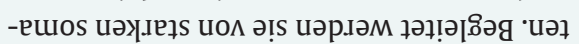

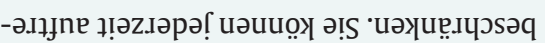

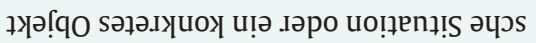
-I!!zวds әu!̣ jne ł

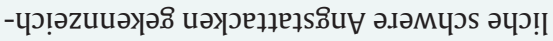

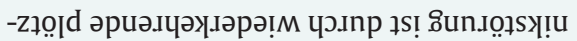
-е $\mathrm{e}_{\mathrm{d}}$ ә!

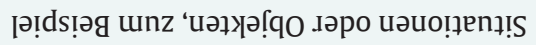

$$
\text { :† } \exists \text { } \mathrm{DY}
$$

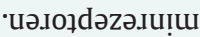

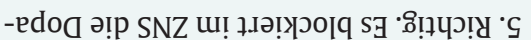
•

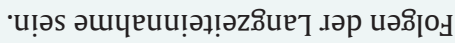

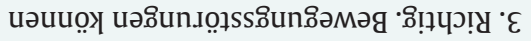

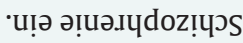

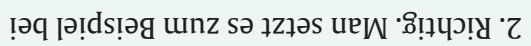
'uny!?

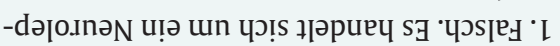

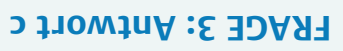

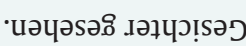

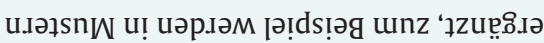

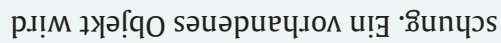

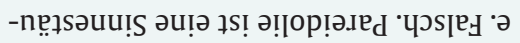

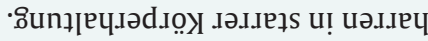
-лә

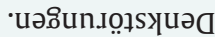

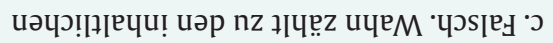

4. Haloperidol kann auch vom Heilpraktiker verordnet werden.

5. Haloperidol wirkt auf den DopaminStoffwechsel.

$\square$ a Aussagen 1, 3 und 4 sind richtig.

$\square$ b Aussagen 1, 4 und 5 sind richtig.

$\square$ c Aussagen 2, 3 und 5 sind richtig.

$\square \mathrm{d}$ Aussagen 1, 3, 4 und 5 sind richtig.

$\square$ e Aussagen 2, 3, 4 und 5 sind richtig.

\section{Mündliche Prüfungsfragen}

\section{FRAGE 4:}

Was unterscheidet eine Phobie von einer Panikstörung?

\section{FRAGE 5:}

Nennen Sie bitte Kriterien für die Diagnose einer Alkoholabhängigkeit!

Dieser Artikel ist online zu finden: http://dx.doi.org/10.1055/a-0655-0831

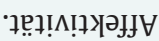

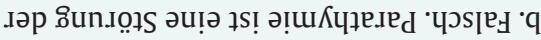

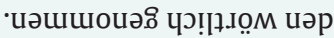

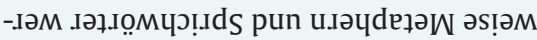

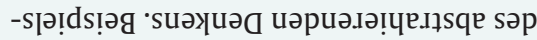

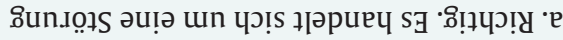

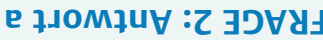

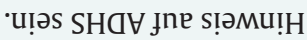

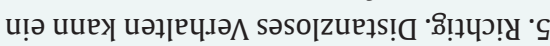
'แวนиวу..І $\mathrm{nz}$

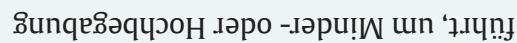

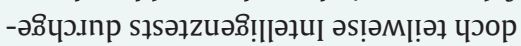

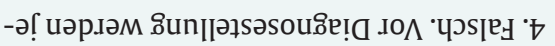

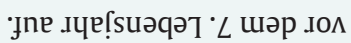

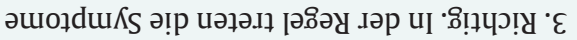

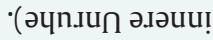

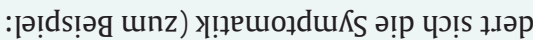

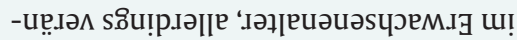

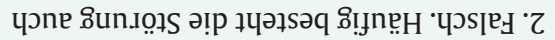

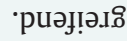

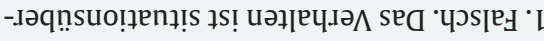

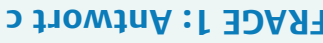

